\title{
The expression of sirtuins, superoxide dismutase, and lipid peroxidation status in peripheral blood from patients with diabetes and hypothyroidism
}

\author{
Abdullah Al-Khaldi and Samar Sultan ${ }^{*}$ iD
}

\begin{abstract}
Background: Sirtuin 1 (SIRT1) and sirtuin 3 (SIRT3) proteins have an important role in counteracting oxidative stress. Although diabetes and hypothyroidism (HT) are both characterized by oxidative stress, the mechanisms are not fully understood. This study investigated the effects of type 1 diabetes (T1D), type 2 diabetes (T2D), and HT on the expression levels of SIRT1, SIRT3, and manganese superoxide dismutase (SOD2).

Methods: Gene expression of SIRT1, SIRT3, and SOD2 was measured using real-time PCR. The protein expression of SOD2 and lipid peroxidation (thiobarbituric acid reactive substances) was measured by the TBARS Assay kit and enzyme-linked immunosorbent assay (ELISA) respectively.

Results: The results showed that the SIRT1 and SIRT3 levels were lower in peripheral blood samples from patients with T1D, T2D, or HT than in healthy individuals. Interestingly, the mRNA and protein expression levels of SOD2 were higher in all three patient groups. Lipid peroxidation was higher in the patients with HT than in the healthy individuals.

Conclusions: These results indicate alterations in the expression levels of sirtuins and superoxide dismutase in diabetes and HT, which may be related, at least in part, to the oxidative stress. Identifying such alterations in those patients will pave the way towards the development of drugs to enhance SIRT1 and SIRT3 expression and their activity to prevent the damaging effect of oxidative stress.
\end{abstract}

Keywords: Sirtuins; Diabetes, Hypothyroidism, Superoxide dismutase, Oxidative stress

\section{Background}

Sirtuins are $\mathrm{NAD}^{+}$-dependent histone/protein deacetylases consist of seven subtypes that are placed in the mitochondria (SIRT3, SIRT4, and SIRT5), nucleus (SIRT1, SIRT6, and SIRT7), and cytoplasm (SIRT2) [1]. Among them, SIRT1 and SIRT3 have the strongest deacetylase activities, whereas the other subtypes have weak or no deacetylase activity [1]. In this study, we focused on SIRT1 and SIRT3 because of their cytoprotective role as antioxidants in reducing oxidative stress.

There is growing evidence supporting the role of sirtuins in responding to oxidative stress through direct

\footnotetext{
* Correspondence: sasultan@kau.edu.sa

Faculty of Applied Medical Sciences, King Abdulaziz University, Jeddah, Saudi
} Arabia

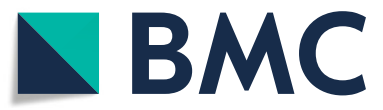

(c) The Author(s). 2019 Open Access This article is distributed under the terms of the Creative Commons Attribution 4.0 International License (http:/creativecommons.org/licenses/by/4.0/) which permits unrestricted use, distribution, and reproduction in any medium, provided you give appropriate credit to the original author(s) and the source, provide a link to the Creative Commons license, and indicate if changes were made. The Creative Commons Public Domain Dedication waiver (http://creativecommons.org/publicdomain/zero/1.0/) applies to the data made available in this article, unless otherwise stated.

deacetylation of transcription factors that regulate antioxidant genes. It has been shown that SIRT1 attenuates oxidative stress in coronary arterial endothelial cells exposed to elevated glucose levels [2] and in rats with streptozotocin-induced diabetes [3]; therefore, SIRT1 may exert protective effects against diabetes and its complications. Downregulation of SIRT1 and increased systemic oxidative stress have been reported in lymphocytes and endothelial progenitor cells of T2D [2, 3]. Besides its role as an antioxidant, SIRT1-along with SIRT3-is the key regulator of glucose homeostasis [4], insulin secretion [5] and mitochondrial biogenesis [6] SIRT3 modulates skeletal muscle mitochondrial metabolism and reactive oxygen species (ROS) production through insulin signaling in T1D and T2D [7]. It also 
stimulates the target gene of PGC- $1 \alpha$, modulates ROS production, and mitochondrial biogenesis [8]. It has been reported that SIRT3 triggers the activation of SOD2, the activity of which is suppressed by the deletion of the SIRT3 gene [7]. In addition, SIRT3 gene knockdown has been shown to increase apoptosis and oxidative stress levels in pancreatic islet-derived beta cells from patients with T2D [9].

Diabetes is a multifactorial complex metabolic disease characterized by impaired metabolism of carbohydrates, lipids, and proteins owing to defects in either insulin action or insulin secretion or both [10]. Worldwide around 171 million were affected by diabetes in 2000 and this is predicted to increase to 366 million in 2030 [11]. There are two major classes of diabetes: T1D and T2D. The main causes of T2D are resistance to the action of insulin accompanied by a deficiency in insulin secretion [12]. T1D is caused by the autoimmune destruction of pancreatic beta cells, resulting in a near-total deficiency of insulin secretion, and individuals with this type of diabetes are required to inject insulin [13, 14]. A disturbance in the balance of ROS levels and the antioxidative defense system, termed oxidative stress, has been shown to be linked to insulin resistance. An increase in ROS levels triggers the activation of stress kinases (e.g., c-Jun $\mathrm{N}$-terminal kinase and protein kinase $\mathrm{C}$ ), which causes the phosphorylation of insulin receptor-1 that in turn accelerates its degradation, leading to oxidative stress-induced insulin resistance [15]. In addition, studies have shown the beneficial effects of antioxidants in reversing insulin resistance and enhancing insulin sensitivity, as reported in patients with T2D who were treated with Vitamin C, Vitamin E, $N$-acetylcysteine, alpha-lipoic acid, and glutathione [16-20].

HT is caused by the reduced activity or production of thyroid hormone $(\mathrm{TH})$, which results in a total decline of the metabolic process [21]. The THs T3 and T4 play key roles in regulating hepatic lipid, cholesterol, and glucose metabolism [22, 23]. Administration of T4 medication has been shown to activate T3, which in turn upregulates the important factors (e.g., SIRT1) that are involved in glucose homeostasis [24]. Furthermore, HT has been shown to be accompanied by oxidative stress $[25,26]$. Increases in the activity of SOD and expression of SOD1 have been evidenced in the kidney of hypothyroid rats during postnatal development and maturation, as compared with the levels in the controls [27]. To the best of our knowledge, there is no study that has investigated SIRT3 levels in patients with HT. Given the roles of SIRT1 and SIRT3 in the regulation of mitochondrial ROS production, this study aimed to elucidate whether alterations on the expression levels of SIRT1, SIRT3, SOD2, and lipid peroxidation status are related to the observed oxidative stress in T1D, T2D, and HT.

\section{Methods}

\section{Subjects}

Blood samples were obtained from 22 patients with T2D (10 males and 12 females), 5 with T1D ( 3 females and 2 males), and 7 with HT (all females), as well as from 13 healthy donors (controls), who attended the diabetic center at King Fahad Armed Forces Hospital during the period from October 2017 - January 2018. The control subjects were non-smokers, did not take medication, did not have high blood pressure or a family history of diabetes. For the diabetic group, subjects with severe disease complications (e.g. myocardial infarction) and/or presenting with both diabetes and HT were excluded. Subjects with a fasting plasma glucose concentration of $>7 \mathrm{mmol} / \mathrm{L}$ and $\mathrm{HbA} 1 \mathrm{c}>6.5 \%$ were considered as diabetic according to the American Diabetes Association [28]. Diabetic group was on insulin alongside different drugs, such as generic metformin, NovoMix, Glucophage, and Lantus. For the HT group, subjects with diabetes and other serious diseases (e.g. cardiac disease) were excluded. Serum thyroid-stimulating hormone (TSH) determination is important for evaluating the function of the thyroid gland. Patients with serum TSH $>6 \mathrm{mIU} / \mathrm{L}$ were classified as having HT. The exclusion of subjects was achieved after clinical assessment and biochemical analysis. All the patients with HT were on thyroxine medication. Patient data including medications, duration of diseases, and anthropometric measurements such as weight, height, and body mass index were recorded from the medical patients' profile. For experiments, including ELISA and TBARS, samples were obtained from a minimum of three individuals from each study group.

\section{Biochemical analysis}

Eight milliliters of peripheral blood sample were collected in two tubes (+EDTA and plain) from participants of all four study groups, after overnight fasting. The EDTA sample was divided into equal volumes for RNA extraction and $\mathrm{HbA1c}$ analysis. A sample of the extracted RNA was analyzed within $6 \mathrm{~h}$ of collection to avoid RNA degradation. Serum from the plain tubes was separated by centrifugation at $3000 \mathrm{~g}$ for $15 \mathrm{~min}$, and split into equal volumes for measurement of biochemical analytes, such as fasting blood glucose, and for other experiments such as ELISA and TBARS. The serum was stored at $-80^{\circ} \mathrm{C}$ until use.

The fasting plasma glucose, TSH and cholesterol concentrations were measured by an automated enzymatic method (Cobas 8000 Modular Analyzer, Roche Diagnostics, Mannheim, Germany). The level of circulating HbA1c was measured by high-performance liquid chromatography (Variant II Turbo, Bio-Rad, Hercules, CA, 
USA). HbA1c normal values have ranged from 4.0 to $6.0 \%$ as reported previously [29].

SOD2 and TBARS serum concentrations were quantified with an ELISA system (SOD2 ELISA, Cusabio Co., Suffolk, UK) and TBARS assay kit (Cayman Chemical, Ann Arbor, MI, USA), respectively, following the manufacturers' instructions.

\section{RNA extraction and real-time PCR}

Total cellular RNA was isolated from the blood samples in EDTA tubes using the MagNA Pure Compact RNA Isolation Kit (Roche Diagnostics, $\mathrm{GmbH}$ ) on the automatic isolator MagNA Pure Compact (Roche Diagnostics, GmbH). $1 \mu \mathrm{g}$ of RNA was used to synthesize cDNA using an ImProm-II Reverse Transcription System kit (Promega, Southampton, UK), according to the manufacturer's instruction. The sequences of SIRT1, SIRT3, $S O D 2$, and beta-actin (reference gene) primers were as stated in our previously published study [30]. The mRNA levels among the samples were normalized to the corresponding results of the internal control Beta-actin mRNA. A QuantiTect SYBR Green PCR kit (Qiagen, Manchester, UK) was used to perform the amplification in duplicate, in the iCycleriQ Real-Time PCR Detection System (Applied Biosystem, Cheshire, UK), following the manufacturer's protocols. Relative expression quantification was calculated using Rest 2009 version 2.0.13 software [31].

\section{Data analysis}

Normally of distributions was checked by Shapiro-Wilk test and Kolmogorov-Smirnov and QQ plot. Data were compared between two groups using unpaired student's $\mathrm{t}$-test and the results were expressed as the mean \pm SEM. Qualitative variables were expressed as percentages and $p$-values less than 0.05 were considered statistically significant. Statistical calculations were performed using GraphPad Prism Software Version 8.0 (GraphPad Software, Inc., USA).

\section{Results}

Fasting plasma glucose level was significantly higher in the T1D and T2D groups than in the healthy control group. The average age of the patients in the T2D group was also significantly higher than that in the healthy controls. There were no statistically significant differences in these above parameters between the HT and control group (Table 1). The serum level of TBARS was significantly higher in the HT group than in the healthy controls $(P=0.01, n=3)$, as revealed in Table 1. Furthermore, there was not a statistically significant increase in the TBARS levels in the T2D group and no difference in those in the T1D group compared with the levels in the control group (Table 1). The expression of SIRT1 mRNA level was significantly lower $(0.526$-fold, $P=0.032, n=13-22)$ in the patients with T2D than in the control group (Fig. 1). Similar levels were also observed in the patients with T1D (0.252-fold, $P=0.006 n=5-13)$ and HT (0.385-fold, $P$ $=>0.008, n=7-13)$ relative to those in the control group (Fig. 1). Interestingly, there was a significant decrease in the SIRT3 mRNA level in the T2D group compared with that in the control group (0.426-fold, $P=0.048, n=13-22)$ (Fig. 2). The patients with T1D (0.027-fold, $P<0.001, n=5-13)$ and HT (0.084-fold, $P<0.001, n=7-13$ ) also displayed a significantly lower level of SIRT3 mRNA than the control group

Table 1 Clinical characteristics of subjects participating in the study

\begin{tabular}{|c|c|c|c|c|c|}
\hline Status mothers & $\begin{array}{l}\text { Controls } \\
(n=13)\end{array}$ & $\begin{array}{l}\text { T2D } \\
(n=22)\end{array}$ & $\begin{array}{l}\text { T1D } \\
(n=5)\end{array}$ & $\begin{array}{l}\mathrm{HT} \\
(n=7)\end{array}$ & $p$ (T2D /T1D/HT) vs. controls) \\
\hline Age (years) & $45 \pm 0.8$ & $54 \pm 0.3$ & $29.2 \pm 3$ & $38 \pm 1.5$ & $\mathbf{0 . 0 2} / 0.12 / 0.3$ \\
\hline \multicolumn{6}{|l|}{ Sex } \\
\hline Female [n (\%)] & $6(46)$ & $12(55)$ & $2(40)$ & $7(100)$ & \\
\hline Male $[\mathrm{n}(\%)]$ & $7(54)$ & $10(45)$ & $3(60)$ & & \\
\hline Duration (years) & & $12 \pm 0.2$ & $14 \pm 0.1$ & $11 \pm 0.8$ & \\
\hline Weight (kg) & $82 \pm 1$ & $79 \pm 0.5$ & $86 \pm 0.1$ & $79 \pm 2$ & $0.07 / 0.4 / 0.9$ \\
\hline BMI & $29 \pm 0.2$ & $30 \pm 0.3$ & $30 \pm 2$ & $32 \pm 0.8$ & $0.5 / 0.4 / 0.4$ \\
\hline $\mathrm{HbA} 1 \mathrm{c}(\%)$ & $5.6 \pm 0.02$ & $8.2 \pm 0.07$ & $10 \pm 0.2$ & & $<0.001 /<0.001$ \\
\hline $\mathrm{FPG}(\mathrm{mM})$ & $4.9 \pm 0.04$ & $10.9 \pm 0.2$ & $11 \pm 0.3$ & $4.7 \pm 0.06$ & $<0.001 /<0.001 / 0.2$ \\
\hline $\mathrm{TSH}(\mathrm{mlU} / \mathrm{L})$ & & & & $9.12 \pm 2$ & \\
\hline Cholesterol (mmol/L) & & $4.2 \pm 0.04$ & & $4.50 \pm 0.1$ & \\
\hline $\begin{array}{l}\text { TBARS } \\
(\mathrm{nmol} / \mathrm{mL})\end{array}$ & $\begin{array}{l}7.83 \pm 0.3 \\
(n=3)\end{array}$ & $\begin{array}{l}8.67 \pm 1 \\
(n=3)\end{array}$ & $\begin{array}{l}7.46 \pm 0.7 \\
(n=3)\end{array}$ & $\begin{array}{l}15 \pm 1 \\
(n=3)\end{array}$ & $0.3 / 0.4 / \mathbf{0 . 0 1}$ \\
\hline
\end{tabular}

Data are presented as mean \pm SEM or $\mathrm{n}$. FPG fasting plasma glucose, $B M I$ Body mass index, HbA1c glycosylated hemoglobin, TSH Thyroid stimulating hormone. $\mathrm{n}$ denoted number of sample. Bold number indicated significant data 


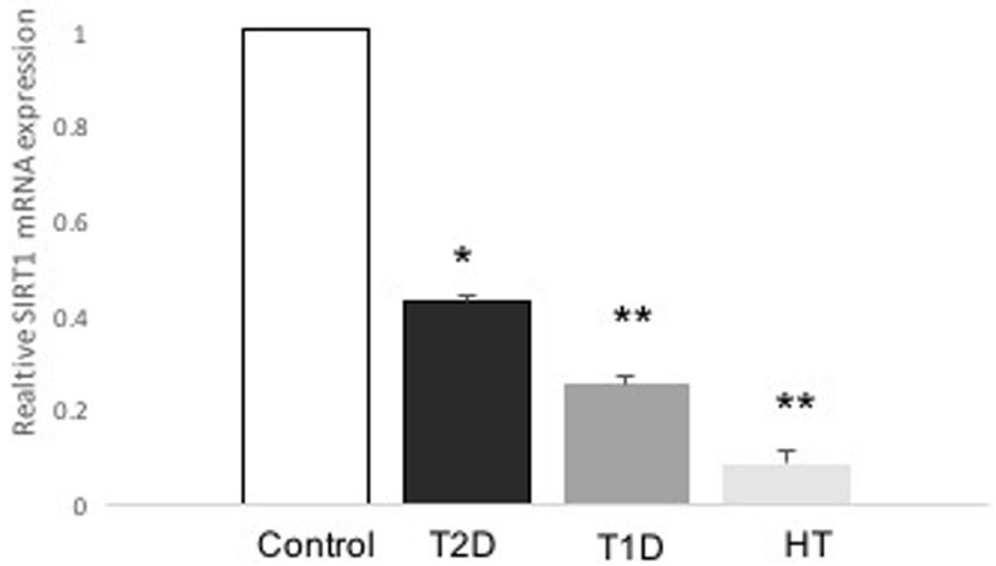

Fig. 1 Expression levels of SIRT1 in patients with T2D, T1D, HT and control individuals. The evaluation of the expression levels of SIRT1 and $\beta$-actin are shown for control $(n=13), \operatorname{T2D}(n=22), \operatorname{T1D}(n=5)$, and HT $(n=7)$. SIRT1 expression was measured by real-time PCR. Data are presented as means \pm SEM. $n$ donated the number of donors. ${ }^{*} P<0.05,{ }^{* *} p<0.01$ versus controls

(Fig. 2). As depicted in Fig. 3, there was a significantly higher level of SOD2 in the T2D group than in the controls (2-fold, $P=0.011, n=13-22)$. Similarly, we observed significantly higher levels of SOD2 mRNA in the T1D (8-fold, $P=0.001$, $n=5-13)$ and HT groups (14-fold, $P<0.001, n=7-13$ ) than in the control group (Fig. 3). As expected, the SOD2 protein level was also significantly higher in the T2D group than in the control group $(P=0.0029, n=4-6)$ (Fig. 4). Similar values were found in the T1D $(P=0.03$, $n=4-6)$ and HT groups $(P=0.03, n=4-6)$ relative to the control group values (Fig. 4).

\section{Discussion}

In this study, we found that the mRNA expression levels of SIRT1 and SIRT3 were decreased in patients with T2D, T1D, and HT, whereas the expression of SOD2 was increased at the mRNA and protein levels in all groups as compared with levels in the control group. These data could explain the genetic link between diabetes and HT.

Diabetes complications occur as a result of excessive free radical production, caused by damage to the antioxidative defenses or radical-induced enzyme inactivation

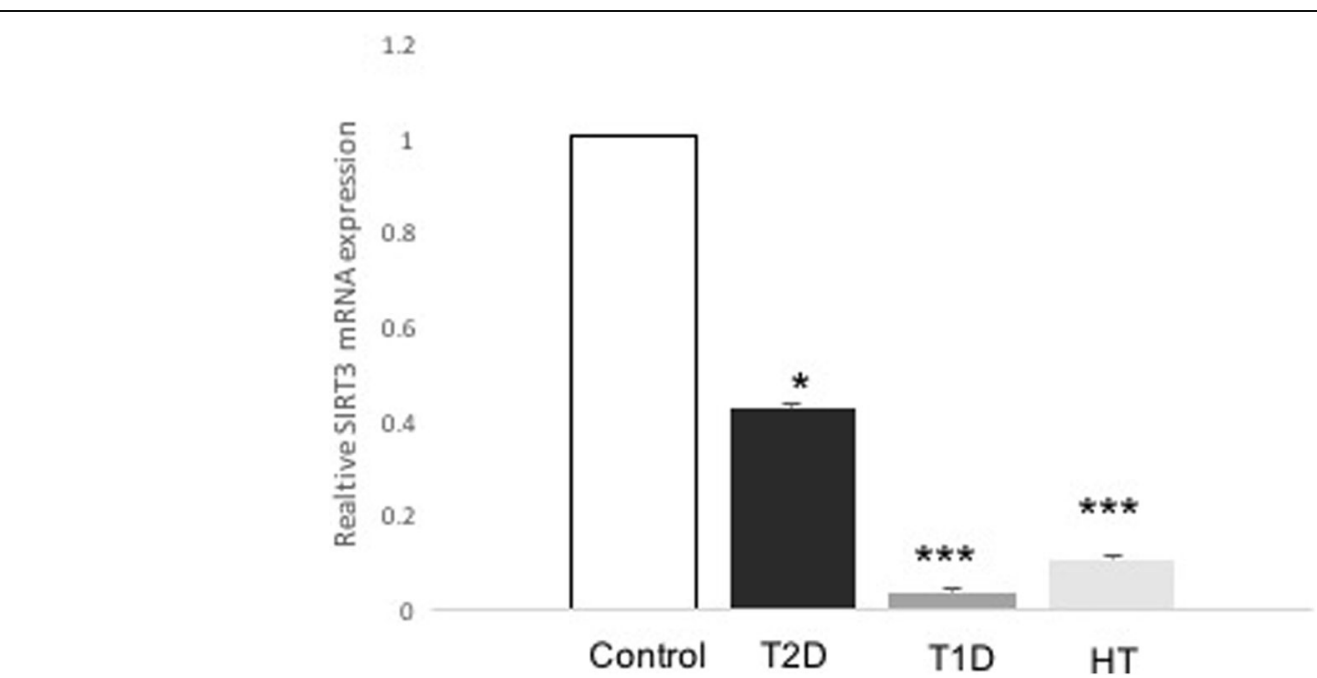

Fig. 2 Expression levels of SIRT3 in patients with T2D, T1D, HT and control individuals. The evaluation of the expression levels of SIRT3 and $\beta$-actin are shown for control $(n=13), \operatorname{T2D}(n=22), \operatorname{T1D}(n=5)$, and HT $(n=7)$. SIRT3 expression was measured by real-time PCR. Data are presented as means \pm SEM. $n$ donated the number of donors. ${ }^{*} p<0.05,{ }^{* *} p<0.001$ versus controls 


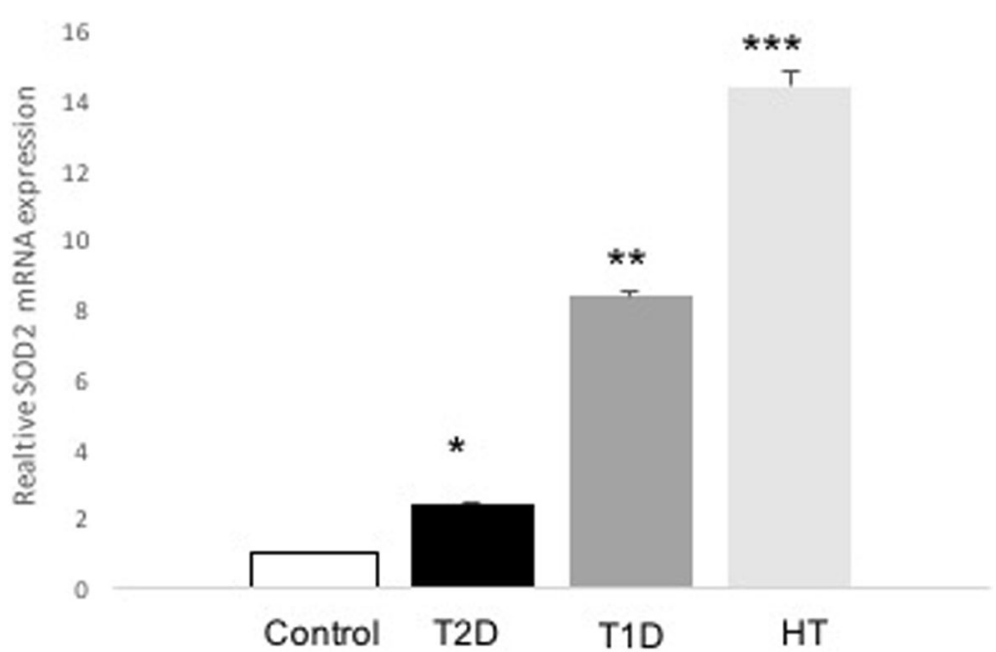

Fig. 3 Expression levels of SOD2 in patients with T2D, T1D, HT, and control individuals. The evaluation of the expression levels of SOD2 and $\beta$ actin are shown for control $(n=13)$, T2D $(n=22), \operatorname{T1D}(n=5)$, and HT $(n=7)$. SOD2 expression was measured by real-time PCR. Data are presented as means \pm SEM. $n$ donated the number of donors. ${ }^{*} p<0.05,{ }^{* *} p<0.01,{ }^{* * *} p<0.001$ versus controls

[32]. Among the sirtuin family members, SIRT1 and SIRT3 proteins are required to reduce oxidative stress, as reported by previous studies [33-35]. In this study, SIRT1 and SIRT3 expression was decreased in T1D and T2D, suggested their roles in the pathogenesis of diabetes. Here, we could only confirm the protein expression of the upregulated genes, as the detection of protein from downregulated genes was below the limit of detection of the ELISA. Our results are consistent with those of a previous study that reported a decrease in SIRT1 activity in lymphocytes derived from patients with T2D [33]. In addition, our previous study showed that SIRT3 mRNA expression was decreased in postpartum women with gestational diabetes mellitus and T2D [30]. The mechanisms behind the low expression of circulating SIRT1 and SIRT3 are not yet fully understood. Recently, it was reported that the expression levels of SIRT1 and SIRT3 mRNA and protein were decreased in the retinas of rats with early-stage diabetes; however, after injection treatment with an antioxidant glucagon-like peptide 1 analog, exendin-4 (EX4), the expression of both SIRT1 and SIRT3 was restored to normal levels [36]. In that same study, the expression levels of SIRT1 and SIRT3 were decreased and the ROS level was increased in a culture system of $\mathrm{H}_{2} \mathrm{O}_{2}$-treated $\mathrm{R} 28$ cells; however, with the addition of EX4, the levels of both sirtuins

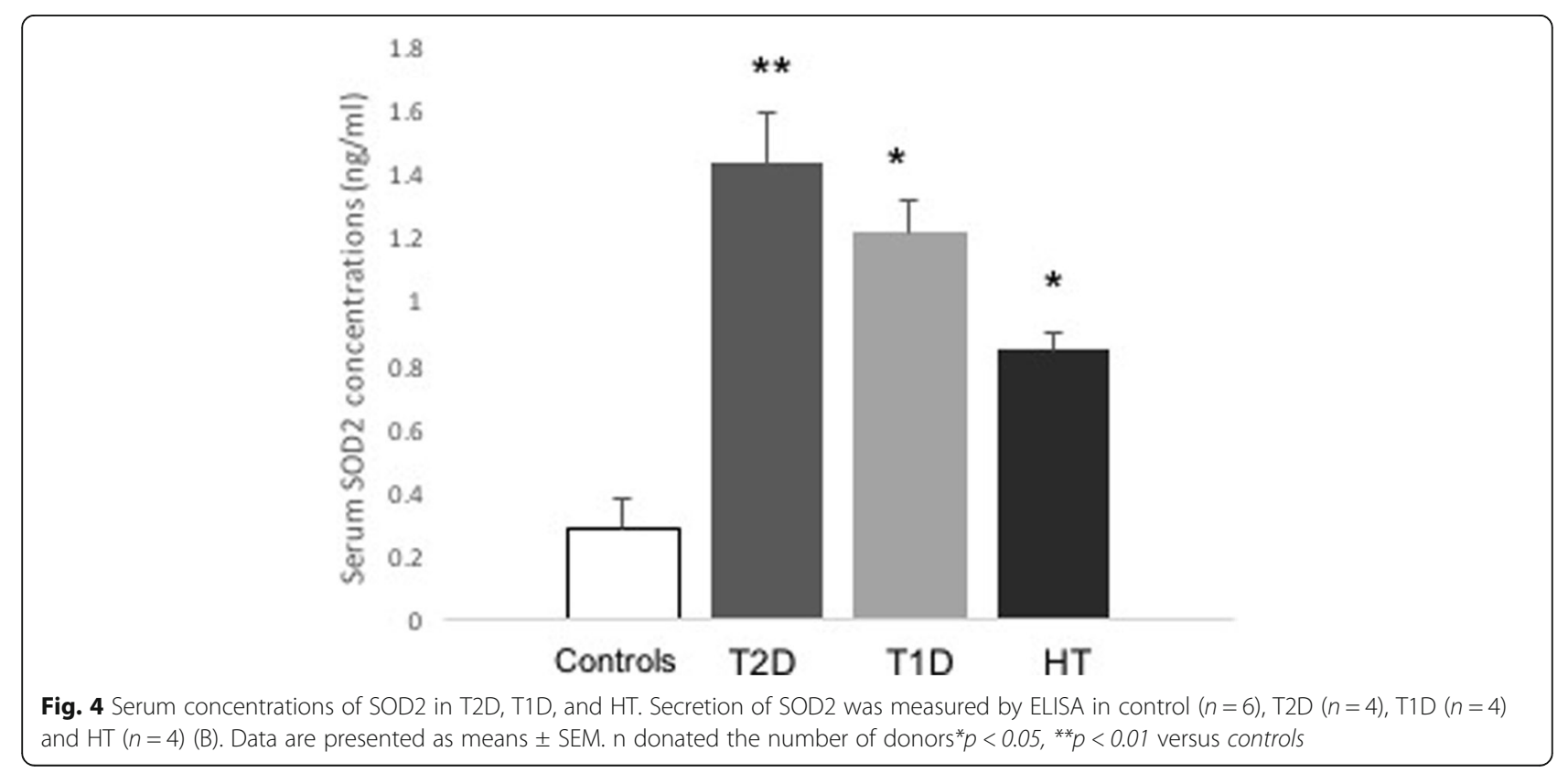


were increased and the ROS level was decreased [36]. It can be inferred from this present study that the observed decrease in SIRT1 and SIRT3 levels in our model may be, at least in part, due to oxidative stress, although we found a nonsignificant increase in lipid peroxidation in the T2D group and no difference in TBARS level between the T1D and control groups.

Interestingly, in this study, the mRNA and protein levels of SOD2, the principle antioxidative enzyme, were higher in both the T1D and T2D groups than in the control group. This result could be explained by a compensatory response to increasing mitochondrial ROS level owing to hyperglycemia in the patients with diabetes, as SOD2 is a mitochondrial free-radical-scavenging enzyme. Nevertheless, there are contradictory findings in the literature regarding the levels of SOD2 in patients with diabetes [37]. Our results are in line with a study conducted by Moussa, which reported increased SOD2 activity in patients with T1D and T2D [38]. However, our results contradicted studies that did not specify the SOD subtype and showed its activity to be lower in patients with T2D than in healthy controls $[39,40]$. These conflicting data could be attributed to the differences in the patients' ethnicity, nutrition, and environment, or the techniques used in each study.

On the other hand, thyroid dysfunction has been shown to be associated with oxidative stress [41-44]. With this perspective, proteins that protect against oxidative stress, such as SIRT1 and SIRT3, may be thought to be affected by low TH levels. With this perspective, proteins that protect against oxidative stress, such as SIRT1 and SIRT3, may be thought to be affected by low $\mathrm{TH}$ levels. Although a limited number of studies have shown the influence of $\mathrm{TH}$ (T3 and T4) on sirtuins, our results are in line with an animal study that used immunohistochemistry to reveal weaker staining of SIRT2 in ganglion cells derived from hypothyroid rat pups [45]. The authors of that study suggested that $\mathrm{TH}$ plays an important role in activating the sirtuin family of proteins, possibly through binding to their receptors. Moreover, it has been shown that reduced SIRT1 expression and activity may lead to diabetes in mice and humans $[46,47]$. As diabetes mellitus is frequently associated with HT, these observed alterations could explain the link between diabetes and HT, based on the similar reduction of sirtuin levels in patients with T1D and T2D in the current study.

Furthermore, the levels of SOD2 in this study were increased at both the mRNA and protein levels in patients with HT relative to the control levels. This could be a compensatory mechanism in response to oxidative stress, as we noticed a higher level of TBARS in the patients with HT than in the control group, suggesting direct damage to the lipid structure by oxidative stress in the patient group. This is in line with a study that showed that the increase in the TBARS level in patients with HT indicated the presence of oxidative stress [48], which might be considered as a risk factor for cardiovascular disease development, similar to diabetes. As HT is often accompanied by diabetes, we selected non-diabetic patients with HT to rule out the effect of diabetes on oxidative stress.

It has been shown that elevated levels of TSH trigger cytokine expression, decrease antioxidant levels [49], and directly increase oxidative stress [50]. The variation in the levels of $\mathrm{TH}$ is the main cause of in vivo oxidative stress, owing to its important role in mitochondrial respiration. Reduced $\mathrm{TH}$ levels have been shown to induce oxidative stress and lipid peroxidation in the liver, heart, and smooth muscle [51], suggesting that HT could be a risk factor for increased oxidative stress, which could lead to other complications, such as diabetes. In the current study, although patients with HT were on thyroxine medication, the damaging effect of HT was only partially reversible with $\mathrm{TH}$ replacement therapy. A previous study showed that neurocognitive functioning in HT patients remained significantly defective despite thyroxine treatment, compared with that of euthyroid controls without HT [52]. Moreover, TH therapy has been shown to augment mitochondrial oxygen consumption and oxidative stress in patients with HT [53, 54]. In line with this, our study showed that oxidative stress is evident in patients with $\mathrm{HT}$ after the administration of thyroxine. Therefore, long-term antioxidant strategies, such as vitamin $\mathrm{E}$ therapy and an antioxidant diet, are advised along with the use of this drug, to protect against any complications that might develop.

This study has some limitations; for example, HbA1c values were not established for patients with HT, and TSH and cholesterol levels were not determined in all groups. In addition, there were no significant differences in characteristics among the study subjects, except for the significant increases in fasting glucose levels and HbAlc in the T1D and T2D groups, and a higher age in the T2D group. This suggested that the observed alterations in genes may be, at least, in part due to hyperglycemia.

\section{Conclusion}

In conclusion, the changes in sirtuin expression, as observed in our study, may explain the failures of the diabetic and HT defense mechanisms against oxidative stress. The finding that SOD2 was increased at the mRNA and protein levels in all groups suggests its role in counteracting the observed oxidative stress in diabetes and HT. Thus, these alterations in the expression levels of sirtuins and superoxide dismutase in diabetes and HT may be related, at least in part, to the oxidative stress. Thus, designing drugs to enhance SIRT1 and SIRT3 
expression and their activity would be useful to protect patients with diabetes and HT against the damaging effect of oxidative stress.

\section{Abbreviations \\ BMI: Body mass index; ELISA: Enzyme-linked immunosorbent assay; FPG: Fasting plasma glucose; HbA1c: Glycosylated hemoglobin: Hypothyroidism; SIRT: Sirtuin; SOD: Superoxide dismutase; T1D: Type 1 diabetes; T2D: Type 2 diabetes; TBARS: Thiobarbituric acid reactive substances; TH: Thyroid hormone; TSH: Thyroid stimulating hormone}

\section{Acknowledgements}

The authors are grateful to donors who donated blood and nurses who helped with samples collection at King Fahad Armed Forces Hospital. We thank the King Abdulaziz City for Science and Technology (KACST) for supporting our study (grant number 0006-009-00-17-1).

\section{Funding}

This work was supported by research grants from the King Abdulaziz City for Science and Technology (KACST) grant no 0006-009-00-17-1.

\section{Availability of data and materials}

The datasets used and/or analysed during the current study available from the corresponding author on reasonable request.

\section{Authors' contributions}

SS conceived and designed the study, performed the data analyses, interpretation of data and wrote the manuscript. AK helped in the design of the study, data collection, and analyses. All authors read and approved the final manuscript.

\section{Ethics approval and consent to participate}

All procedures performed in studies involving human participants were in accordance with the ethical standards of the institutional and/or national research committee and with the 1964 Helsinki declaration and its later amendments or comparable ethical standards. Approval of the study was given by the Ethics Committee of the King Fahad Armed Forces Hospital, Jeddah, Saudi Arabia. Informed written consent was obtained from all individual participants included in the study.

\section{Consent for publication}

Not applicable.

\section{Competing interests}

The authors declare that they have no competing interests.

\section{Publisher's Note}

Springer Nature remains neutral with regard to jurisdictional claims in published maps and institutional affiliations.

\section{Received: 23 September 2018 Accepted: 4 February 2019}

\section{Published online: 08 February 2019}

\section{References}

1. Merksamer PI, Liu Y, He W, Hirschey MD, Chen D, Verdin E. The sirtuins, oxidative stress and aging: an emerging link. Aging (Albany NY). 2013;5(3):144-50.

2. Ungvari Z, Labinskyy N, Mukhopadhyay P, Pinto JT, Bagi Z, Ballabh P, Zhang C, Pacher P. Csiszar A. Resveratrol attenuates mitochondrial oxidative stress in coronary arterial endothelial cells. Am J Physiol Heart Circ Physiol. 2009; 297(5):H1876-81.

3. Gencoglu H, Tuzcu M, Hayirli A, Sahin K. Protective effects of resveratrol against streptozotocin-induced diabetes in rats by modulation of visfatin/sirtuin-1 pathway and glucose transporters. Int J Food Sci Nutr. 2015;66(3):314-20,

4. Price NL, Gomes AP, Ling AJY, Duarte FV, Martin-Montalvo A, North BJ, Agarwal B, Ye L, Ramadori G, Teodoro JS. SIRT1 is required for AMPK activation and the beneficial effects of resveratrol on mitochondrial function. Cell Metab. 2012;15(5):675-90.

5. Sun C, Zhang F, Ge X, Yan T, Chen X, Shi X, Zhai Q. SIRT1 improves insulin sensitivity under insulin-resistant conditions by repressing PTP1B. Cell Metab. 2007;6(4):307-19
6. Brenmoehl J, Hoeflich A. Dual control of mitochondrial biogenesis by sirtuin 1 and sirtuin 3. Mitochondrion. 2013;13(6):755-61.

7. Jing E, Emanuelli B, Hirschey MD, Boucher J, Lee KY, Lombard D, Verdin EM, Kahn CR. Sirtuin-3 (Sirt3) regulates skeletal muscle metabolism and insulin signaling via altered mitochondrial oxidation and reactive oxygen species production. Proc Natl Acad Sci. 2011;108(35):14608-13.

8. Liu J, Li D, Zhang T, Tong Q, Ye RD, Lin L. SIRT3 protects hepatocytes from oxidative injury by enhancing ROS scavenging and mitochondrial integrity. Cell Death Dis. 2017;8(10):e3158.

9. Caton PW, Richardson SJ, Kieswich J, Bugliani M, Holland ML, Marchetti P, Morgan NG, Yaqoob MM, Holness MJ, Sugden MC. Sirtuin 3 regulates mouse pancreatic beta cell function and is suppressed in pancreatic islets isolated from human type 2 diabetic patients. Diabetologia. 2013;56(5):1068-77.

10. Alberti K, Zimmet PZ, Consultation WHO. Definition, diagnosis and classification of diabetes mellitus and its complications. Part 1: diagnosis and classification of diabetes mellitus. Provisional report of a WHO consultation. Diabet Med. 2004:15(7):539-53.

11. Wild S, Roglic G, Green A, Sicree R, King H. Global prevalence of diabetes. Diabetes Care. 2004:27(5):1047.

12. DeFronzo RA. Pathogenesis of type 2 diabetes: metabolic and molecular implications for identifying diabetes genes. Diabetes Rev. 1997;5(3):177-269.

13. Eisenbarth GS, Nayak RC, Rabinowe SL. Type I diabetes as a chronic autoimmune disease. J Diabet Complicat. 1988:2(2):54-8.

14. Baekkeskov S, Landin M, Kristensen JK, Srikanta S, Bruining GJ, MandrupPoulsen T, De Beaufort C, Soeldner JS, Eisenbarth G, Lindgren F. Antibodies to a $64,000 \mathrm{Mr}$ human islet cell antigen precede the clinical onset of insulindependent diabetes. J Clin Investig. 1987;79(3):926.

15. Aguirre V, Werner ED, Giraud J, Lee YH, Shoelson SE, White MF. Phosphorylation of Ser307 in insulin receptor substrate-1 blocks interactions with the insulin receptor and inhibits insulin action. J Biol Chem. 2002;277(2):1531-7.

16. Kamenova P. Improvement of insulin sensitivity in patients with type 2 diabetes mellitus after oral administration of alpha-lipoic acid. Hormones (Athens). 2006;5(4):251

17. Hirai N, Kawano H, Hirashima O, Motoyama T, Moriyama Y, Sakamoto T, Kugiyama K, Ogawa H, Nakao K, Yasue H. Insulin resistance and endothelial dysfunction in smokers: effects of vitamin C. Am J Phys Heart Circ Phys. 2000;279(3):H1172-8

18. Caballero B. Vitamin E improves the action of insulin. Nutr Rev. 1993:51(11):339-40.

19. Paolisso G, Di Maro G, Pizza G, D'Amore A, Sgambato S, Tesauro P, Varricchio M, D'Onofrio F. Plasma GSH/GSSG affects glucose homeostasis in healthy subjects and non-insulin-dependent diabetics. Am J Physiol. 1992;263(3):E435-40.

20. Haber CA, Lam TKT, Yu Z, Gupta N, Goh T, Bogdanovic E, Giacca A, Fantus IG. N-acetylcysteine and taurine prevent hyperglycemia-induced insulin resistance in vivo: possible role of oxidative stress. Am J Physiol Endocrinol Metab. 2003;285(4):E744-53.

21. Staub JJ, Althaus BU, Engler H, Ryff AS, Trabucco P, Marquardt K, Burckhardt D. Girard J, Weintraub BD. Spectrum of subclinical and overt hypothyroidism: effect on thyrotropin, prolactin, and thyroid reserve, and metabolic impact on peripheral target tissues. Am J Med. 1992:92(6):631-42.

22. Moreno M, de Lange P, Lombardi A, Silvestri E, Lanni A, Goglia F. Metabolic effects of thyroid hormone derivatives. Thyroid. 2008;18(2):239-53.

23. Mullur R, Liu YY, Brent GA. Thyroid hormone regulation of metabolism. Physiol Rev. 2014;94(2):355-82.

24. Vazquez-Anaya G, Martinez B, Sonanez-Organis JG, Nakano D, Nishiyama A, Ortiz RM. Exogenous thyroxine improves glucose intolerance in insulinresistant rats. J Endocrinol. 2017;232(3):501-11.

25. Fayadat L, Niccoli-Sire P, Lanet J, Franc J-L. Role of heme in intracellular trafficking of thyroperoxidase and involvement of $\mathrm{H} 2 \mathrm{O} 2$ generated at the apical surface of thyroid cells in autocatalytic covalent heme binding. J Biol Chem. 1999;274(15):10533-8.

26. Novakovic TR, Dolicanin ZC, Djordjevic NZ. Oxidative stress biomarkers in amniotic fluid of pregnant women with hypothyroidism. J Matern Fetal Neonatal Med. 2019;32(7):1105-10.

27. Jena S, Chainy GB, Dandapat J. Hypothyroidism modulates renal antioxidant gene expression during postnatal development and maturation in rat. Gen Comp Endocrinol. 2012:178(1):8-18

28. Handelsman Y, Mechanick J, Blonde L, Grunberger G, Bloomgarden Z, Bray G, Dagogo-Jack S, Davidson J, Einhorn D, Ganda O. American Association of Clinical Endocrinologists Medical Guidelines for clinical practice for developing a diabetes mellitus comprehensive care plan: executive summary. Endocr Pract. 2011;17(2):287-302. 
29. Heap J, Murray MA, Miller SC, Jalili T, Moyer-Mileur L. Alterations in bone characteristics associated with glycemic control in adolescents with type 1 diabetes mellitus. J Pediatr. 2004;144(1):56-62.

30. Sultan S, Alzahrani N, Al-Sakkaf K. The postpartum effect of maternal diabetes on the circulating levels of sirtuins and superoxide dismutase. FEBS Open Bio. 2018;8(2):256-63.

31. Pfaffl MW. Relative expression software tool (REST(C)) for group-wise comparison and statistical analysis of relative expression results in real-time PCR. Nucleic Acids Res. 2002;30(9):36e-36.

32. Matough FA, Budin SB, Hamid ZA, Alwahaibi N, Mohamed J. The role of oxidative stress and antioxidants in diabetic complications. Sultan Qaboos Univ Med J. 2012;12(1):5-18.

33. Calabrese V, Cornelius C, Leso V, Trovato-Salinaro A, Ventimiglia B, Cavallaro M, Scuto M, Rizza S, Zanoli L, Neri S, et al. Oxidative stress, glutathione status, sirtuin and cellular stress response in type 2 diabetes. Biochim Biophys Acta. 2012;1822(5):729-36.

34. Balestrieri ML, Servillo L, Esposito A, D'Onofrio N, Giovane A, Casale R, Barbieri M, Paolisso P, Rizzo MR, Paolisso G, et al. Poor glycaemic control in type 2 diabetes patients reduces endothelial progenitor cell number by influencing SIRT1 signalling via platelet-activating factor receptor activation. Diabetologia. 2013;56(1):162-72

35. Kong X, Wang R, Xue Y, Liu X, Zhang H, Chen Y, Fang F, Chang Y. Sirtuin 3, a new target of PGC-1alpha, plays an important role in the suppression of ROS and mitochondrial biogenesis. PLoS One. 2010;5(7):e11707.

36. Zeng Y, Yang K, Wang F, Zhou L, Hu Y, Tang M, Zhang S, Jin S, Zhang J, Wang J. The glucagon like peptide 1 analogue, exendin-4, attenuates oxidative stress-induced retinal cell death in early diabetic rats through promoting Sirt1 and Sirt3 expression. Exp Eye Res. 2016;151:203-11.

37. Moussa S. Oxidative stress in diabetes mellitus. Rom J Biophys. 2008;18(3):225-36.

38. Cederberg J, Galli J, Luthman H, Eriksson UJ. Increased mRNA levels of MnSOD and catalase in embryos of diabetic rats from a malformation-resistant strain. Diabetes. 2000:49(1):101-7.

39. Čolak E, Dimitrijević-Srećković $V$, Djordjević PB, Stanković $S$, Glišić B, Srećković B, Majkić-Singh N. Biomarkers of enzymatic and non-enzymatic antioxidative defense in type 2 diabetes mellitus-comparative analysis. Biochemia medica: Biochemia medica. 2008;18(1):42-51.

40. Rahbani-Nobar M, Rahimi-Pour A, Rahbani-Nobar M, Adi-Beig F, Mirhashemi S. Total antioxidant capacity, superoxide dismutase and glutathione peroxidase in diabetic patients. Med J Islam Acad Sci. 1999;12(4):109-14.

41. Katyare SS, Rajan RR. Influence of thyroid hormone treatment on the respiratory activity of cerebral mitochondria from hypothyroid rats. A critical re-assessment. Exp Neurol. 2005;195(2):416-22.

42. Messarah M, Boumendjel A, Chouabia A, Klibet F, Abdennour C, Boulakoud MS, El Feki A. Influence of thyroid dysfunction on liver lipid peroxidation and antioxidant status in experimental rats. Exp Toxicol Pathol. 2010;62(3):301-10.

43. Sarandol E, Tas S, Dirican M, Serdar Z. Oxidative stress and serum paraoxonase activity in experimental hypothyroidism: effect of vitamin $E$ supplementation. Cell Biochem Funct. 2005;23(1):1-8.

44. Erdamar $H$, Demirci $H$, Yaman $H$, Erbil MK, Yakar T, Sancak B, Elbeg $S_{\text {, }}$ Biberoğlu G, Yetkin I. The effect of hypothyroidism, hyperthyroidism, and their treatment on parameters of oxidative stress and antioxidant status. Clin Chem Lab Med. 2008;46(7):1004-10.

45. Kocaturk T, Ergin K, Cesur G, Evlicoglu GE, Cakmak H. The effect of methimazole-induced postnatal hypothyroidism on the retinal maturation and on the Sirtuin 2 level. Cutan Ocul Toxicol. 2016:35(1):36-40.

46. Chalkiadaki A, Guarente L. High-fat diet triggers inflammation-induced cleavage of SIRT1 in adipose tissue to promote metabolic dysfunction. Cell Metab. 2012;16(2):180-8.

47. Biason-Lauber A, Boni-Schnetzler M, Hubbard BP, Bouzakri K, Brunner A Cavelti-Weder C, Keller C, Meyer-Boni M, Meier DT, Brorsson C, et al. Identification of a SIRT1 mutation in a family with type 1 diabetes. Cell Metab. 2013;17(3):448-55.

48. Nanda N, Bobby Z, Hamide A, Koner BC, Sridhar MG. Association between oxidative stress and coronary lipid risk factors in hypothyroid women is independent of body mass index. Metab Clin Exp. 2007;56(10):1350-5.

49. Carmeli E, Bachar A, Barchad S, Morad M, Merrick J. Antioxidant status in the serum of persons with intellectual disability and hypothyroidism: a pilot study. Res Dev Disabil. 2008:29(5):431-8.

50. Haribabu A, Reddy VS, Pallavi C, Bitla AR, Sachan A, Pullaiah P, Suresh V, Rao PS, Suchitra M. Evaluation of protein oxidation and its association with lipid peroxidation and thyrotropin levels in overt and subclinical hypothyroidism Endocrine. 2013;44(1):152-7.

51. Nanda N, Bobby Z, Hamide A. Association of thyroid stimulating hormone and coronary lipid risk factors with lipid peroxidation in hypothyroidism. Clin Chem Lab Med. 2008;46(5):674-9.

52. Wekking EM, Appelhof BC, Fliers E, Schene AH, Huyser J, Tijssen JG, Wiersinga WM. Cognitive functioning and well-being in euthyroid patients on thyroxine replacement therapy for primary hypothyroidism. Eur J Endocrinol. 2005;153(6):747-53

53. Tomella C, Catanzaro R, Illuzzi N, Cabeca A, Zerbinati N, Celep G, Milazzo M, Sapienza C, Italia A, Lorenzetti A. The hidden phenomenon of oxidative stress during treatment of subclinical-mild hypothyroidism: a protective nutraceutical intervention. Rejuvenation Res. 2014;17(2):180-3.

54. Cornelli U, Belcaro G, Ledda A, Feragalli B. Oxidative stress following administration of levothyroxine in subjects suffering from primary hypothyroidism. Panminerva Med. 2011;53(3 Suppl 1):95-8.

\section{Ready to submit your research? Choose BMC and benefit from:}

- fast, convenient online submission

- thorough peer review by experienced researchers in your field

- rapid publication on acceptance

- support for research data, including large and complex data types

- gold Open Access which fosters wider collaboration and increased citations

- maximum visibility for your research: over $100 \mathrm{M}$ website views per year

At $\mathrm{BMC}$, research is always in progress.

Learn more biomedcentral.com/submissions 